\title{
Social scientists and sociobiologists get their lines crossed
}

\section{Jon Seger}

Sociobiology Examined. Edited by Ashley Montagu*. Pp.272. ISBN hbk 0-19502711-6; ISBN pbk 0-19-502712-4. (Oxford University Press: 1980.) Hbk $£ 12.50, \$ 19.95$; pbk £2.95, \$5.95.

Sociobiology Examined is a collection of 16 articles, half of which have been or will be published elsewhere. The authors are listed below. According to the dust jacket, "the articles ... examine the claims [E.O.] Wilson makes for [human] sociobiology [in Sociobiology and On Human Nature] and, by a critical examination of the evidence (or lack of it) on which these claims are based, assess their validity". In only a few of the articles is there a sustained attempt to do this. Some are mostly polemical, in places irresponsibly so; some are mostly about subjects other than sociobiology. For example, Layzer's article turns out to be a detailed critique of Piaget's theory of cognitive development. Sheehan's is a review of recent books on political philosophy by Bernard HenriLevy and Alain de Benoist, neither of whom appears to have the slightest idea what sociobiology is or says, except that someone told them it supports their opinions. Most of the articles stick more closely to the stated subject than do these, but taken as a whole they give the impression that "sociobiology" is more of a Rorschach test than it is a theory or even a well-defined point of view. Midgley comes to a similar conclusion in her essay on the first few years of the "debate" on sociobiology. Although the articles present a bewildering range of views, two major themes come up fairly of ten. One concerns the supposed social, political or ethical implications of sociobiological theories, and the other the issue of genetic determinism.

In agreement with Plato, Hobbes, Rousseau and Wilson, most commentators on sociobiology seem to believe that a theoretically and empirically adequate description of human nature necessarily implies a morally compelling prescription for the organization of human society. The lone dissenter in Sociobiology Examined is Mackintosh, whose article was first published as a review of On Human Nature (Science 204, 735; 1979). "The gap between 'is' and 'ought' remains as wide today as it was when Hume pointed it out 200 years ago". Mackintosh quotes Wilson's claim that "a correct application

* Articles by Jerome H. Barkow, S.A. Barnett, Derek Freeman, Stephen Jay Gould, Marvin Harris, James C. King, David Layzer, N.J. Mackintosh, Mary Midgley, Ashley Montagu, Karl Peter and Nicholas Petryszak, Stephen Rose, Thomas Sheehan, Michael A. Simon and S.L. Washburn. of evolutionary theory . . . favors diversity in the gene pool as a cardinal value", and notes that this is only one of several places where Wilson states or implies that a value can be derived from a fact. But as Mackintosh also notes, Wilson's "radical" critics appear to be even more committed to the naturalistic fallacy than he is. It is truly incredible that in six years of heated "debate"' there has been hardly any serious discussion of this problem.

The question of genetic determinism is much more complex. As Midgley points out, "determinism" is simply a belief in the efficacy of causes. Thus unless you are a dedicated supernaturalist, or believe in at most one cause, it is silly to accuse someone of being a "determinist". As a matter of logic this is true enough, but the social scientists appear to have something more concrete in mind when they speak of genetic or biological determinism. Unfortunately, few of the authors in Sociobiology Examined ever state explicitly what they mean by phrases like "genetic basis", but by the end of the book it has become clear that many of them believe sociobiology attempts to map differences of behaviour, whether between individuals or societies, onto corresponding differences of genotype. In other words, any variability that has a "biological"' explanation is necessarily heritable. This belief can be seen clearly in the article by Simon.

Behavior that can plausibly be designated as innate or instinctive must be stable throughout a range of environments .... Human social behavior ... varies considerably from one social group to another. Social science is typically interested in explaining these variations . . . . If the determinants of the specific differences among a widely disparate range of behavior are not biological but sociocultural, it will not explain any of them to subsume them all under a common biological rubric.

Sociobiology does, in part, attempt to explain behavioural variation. But does it really argue for the heritability of such variation? Those who think that sociobiological theory derives from traditional behaviour genetics say "yes"; this group includes most of the authors in the present collection, but very few sociobiologists. Those who identify sociobiology with the newer work on sex ratios, sexual dimorphism, kin-directed altruism, life-history strategies and the like, say "no"; this group includes most sociobiologists, but in the present collection only Barkow, who notes that "Evolutionary biology does not require ... a direct link . . . between a particular gene and a particular behavior, even if careless reading (and writing) of sociobiology may occasionally permit that impression". There is no contradiction in this as long as different levels of causation are properly distinguished. Barkow's discussion of the levels of causation needed to explain human behaviour is well worth reading. He observes, as have many others, that selection may often favour behavioural flexibility of a kind "mediated by learning preferences". There would be little point to flexibility unless it enabled an individual to recognize and seize unique opportunities. Consistent with this general expectation, animals in learning experiments tend to master some associations much more easily than others. If sociobiology is really about the evolution of learning and other environmentally mediated developmental processes, then at the level of differences between individuals it is, ironically, a theory of environmental determination. Individual differences map onto differences of environment, not of genotype, although they do so according to a logic that is "genetic" in the sense that it reflects innate, evolved characteristics of the species. Thus only at the level of differences between species is sociobiology inherently a theory of genetic determination. Given these contrasting views of "sociobiology", and given the distinctions on which they turn, any simple reference to a genetic substrate, basis, cause, determination or the like, unless carefully specified, is almost certain to be literally meaningless. Because these key terms are seldom specified in the pages of Sociobiology Examined the reader of ten cannot tell just where a given piece of criticism is supposed to strike.

Without a doubt the sociobiologists are partly responsible for this widespread confusion regarding levels of causation and explanation. Mackintosh rightly criticizes Wilson for shifting between different senses of "the notion of genetic determination", and more generally for not giving us "a serious and sustained attempt to analyze in just what sense our behavior or social organization is genetically determined ....". But if Wilson's writing is careless or confused about something so fundamental, why should that of his sharpest critics be even more so? Surely critics have a responsibility to expose weaknesses, rather than to hide them.

Several observers of the sociobiology controversy have remarked that the participants seem to be talking past each other. Unfortunately, Sociobiology Examined does more to document this situation than to change it. The book will be of interest to historians and sociologists of science. But for the most part it will be of little help to those who are still wondering how the study of animal behaviour may ultimately improve the study of human behaviour, and vice versa.

Jon Seger is at the Biological Laboratories, Harvard University. 